\title{
EXISTENCE RESULTS AND CONTINUITY DEPENDENCE OF SOLUTIONS FOR FRACTIONAL EQUATIONS
}

\author{
José VAnTerler da Costa Sousa
}

\begin{abstract}
Using two fractional-order integral inequalities we investigate the existence and uniqueness of solutions of the fractional nonlinear Volterra integral equation and the fractional nonlinear integrodifferential equation in Banach space $C_{\xi}$, using an adequate norm, $\|\cdot\|_{\xi, \infty}$. Besides, we study the solution estimate and investigate their continuous dependence.
\end{abstract}

\section{Mathematics subject classification (2010): 26A33, 34A08, 34A12, 34A60, 34G20.}

Keywords and phrases: Fractional differential equations, fractional integrodifferential, existence and uniqueness, estimate and continuous dependence.

\section{REFERENCES}

[1] S. Abbas, M. Benchohra, J. E. Lagreg, A. Als aedi, Y. Zhou, Existence and Ulam stability for fractional differential equations of Hilfer-Hadamard type, Adv. in Diff. Equa. 2017 (1), (2017), 180.

[2] S. AbBas, M. BEnchohra, Existence and attractivity for fractional order integral equations in Fréchet spaces, Discussiones Mathematicae, Differential Inclusions, Control Opt. 33 (1), (2013), 47 63.

[3] R. Agarwal, S. Jain, R. P. Agarwal, Solution of fractional Volterra integral equation and nonhomogeneous time fractional heat equation using integral transform of pathway type, Progr. Fract. Diff. Appl 1, (2015), 145-155.

[4] R. P. Agarwal, S. Arshad, D. O'Regan, V. Lupulescu, Fuzzy fractional integral equations under compactness type condition, Fract. Calc. Appl. Anal. 15 (4), (2012), 572-590.

[5] A. Aghajani, Y. Jalilian, J. J. Trujillo, On the existence of solutions of fractional integrodifferential equations, Frac. Cal. Appl. Anal. 15 (1), (2012), 44-69.

[6] B. AhmAD, J. J. Nieto, A. Als AEdi, Existence and uniqueness of solutions for nonlinear fractional differential equations with non-separated type integral boundary conditions, Acta Math. Sci. 31 (6), (2011), 2122-2130.

[7] B. AHMAD, J. J. NiETo, Boundary value problems for a class of sequential integrodifferential equations of fractional order, J. Function Spaces Appl. 2013.

[8] B. Ahmad, J. J. Nieto, J. Pimentel, Some boundary value problems of fractional differential equations and inclusions, Comput. Math. Appl. 62 (3), (2011), 1238-1250.

[9] R. Almeida, Fractional differential equations with mixed boundary conditions, Bull. Malaysian Math. Sci. Soc. (2017), 1-11.

[10] A. Anguraj, P. Karthikeyan, M. Rivero, J. J. Trujillo, On new existence results for fractional integro-differential equations with impulsive and integral conditions, Comput. Math. Appl. 66 (12), (2014), 2587-2594.

[11] K. BALACHANDRAN, N. ANNAPOORANI, Existence results for impulsive neutral evolution integrodifferential equations with infinite delay, Nonl. Anal. 3 (4), (2009), 674-684.

[12] K. Balachandran, S. Kiruthika, J. J. Trujillo, Remark on the existence result for fractional impulsive integrodifferential equations in Banach spaces, Commun. Nonlinear Sci. Numer. Simulat. 17 (6), (2012), 2244-2247. 
[13] K. BAlachandran, S. Kiruthika, J. J. Trujillo, Existence results for fractional impulsive integrodifferential equations in Banach spaces, Commun. Nonlinear Sci. Numer. Simulat. 16 (4), (2011), 1970-1977.

[14] M. Benchohra, M. A. DARWish, Existence and uniqueness theorem for fuzzy integral equation of fractional order, Commun. Appl. Anal. 12 (1), (2008), 13-22.

[15] M. Benchohra, J. R. Graef, S. HAmAni, Existence results for boundary value problems with non-linear fractional differential equations, Applicable Anal. 87 (7), (2008), 851-863.

[16] T. BLASZCZYK, J. SieDLECKI, An approximation of the fractional integrals using quadratic interpolation, J. Appl. Math. Comput. Mechanics 13 (4), (2014), 13-18.

[17] T. BlaszczyK, J. Siedlecki, M. Ciesielski, Numerical algorithms for approximation of fractional integral operators based on quadratic interpolation, Math. Meth. Appl. Sci. 41 (9), (2018), $3345-3355$.

[18] N. D. Cong, H. T. TuAn, Existence, uniqueness, and exponential boundedness of global solutions to delay fractional differential equations, Mediterr. J. Math. 14 (5), (2017), 193.

[19] M. A. Darwish, A. A. El-BARY, Existence of fractional integral equation with hysteresis, Appl. Math. Comput. 176 (2), (2006), 684-687.

[20] M. A. DARWISH, On existence and asymptotic behavior of solutions of a fractional integral equation, Applicable Anal. 88 (2), (2009), 169-181.

[21] M. FEC, Y. ZHOU, J. WANG, On the concept and existence of solution for impulsive fractional differential equations, Commun. Nonlinear Sci. Numer. Simulat. 17 (7), (2012), 3050-3060.

[22] H. Gou, B. LI, Local and global existence of mild solution to impulsive fractional semilinear integro-differential equation with noncompact semigroup, Commun. Nonlinear Sci. Numer. Simulat. 42, (2017), 204-214.

[23] R. Herrmann, Fractional Calculus: An Introduction for Physicists, World Scientific Publ. Comp, New Jersey, 2014.

[24] Y. Jalilian, M. Ghasemi, On the solutions of a nonlinear fractional integro-differential equation of pantograph type, Mediterr. J. Math. 14 (5), (2017), 194.

[25] H. Jafari, H. K. Jassim, M. Al Qurashi, D. Baleanu, On the existence and uniqueness of solutions for local fractional differential equations, Entropy 18 (11), (2016), 420.

[26] K. KATHIKEYAN, Existence and uniqueness results for boundary value problems of higher order fractional integro-differential equations involving Gronwall's inequality in Banach spaces, Acta Math. Sci. 33 (3), (2013), 758-772.

[27] A. A. Kilbas, H. M. SRivastava, J. J. Trujillo, Theory and Applications of Fractional Differential Equations, Vol. 204, Elsevier, Amsterdam, 2006.

[28] Z. LIU, X. LI, Existence and uniqueness of solutions for the nonlinear impulsive fractional differential equations, Commun. Nonlinear Sci. Numer. Simulat. 18 (6), (2013), 1362-1373.

[29] F. LI, J. LiANG, H.-K. XU, Existence of mild solutions for fractional integrodifferential equations of Sobolev type with nonlocal conditions, J. Math. Anal. Appl. 391 (2), (2012), 510-525.

[30] K. LI, J. JiA, Existence and uniqueness of mild solutions for abstract delay fractional differential equations, Comput. Math. Appl. 62 (3), (2011), 1398-1404.

[31] M. M. MATAR, J. J. TRUJILlo, Existence of local solutions for differential equations with arbitrary fractional order, Arabian J. Math. 5 (4), (2016), 215-224.

[32] M. T. MALinOwski, Random fuzzy fractional integral equations-theoretical foundations, Fuzzy Sets Sys. 265, (2015), 39-62.

[33] S. Micula, An iterative numerical method for fractional integral equations of the second kind, J. Comput. Appl. Math. 339, (2018), 124-133.

[34] Z. OUYANG, Existence and uniqueness of the solutions for a class of nonlinear fractional order partial differential equations with delay, Comput. Math. Appl. 61 (4), (2011), 860-870.

[35] B. G. PAChPatTE, On certain Volterra integral and integrodifferential equations, Facta. Univ. (Nis) Ser. Math. Infor. 23, (2008), 1-12.

[36] I. Podlubny, Fractional Differential Equations, Mathematics in Science and Engineering, Academic Press, San Diego, Vol. 198, 1999.

[37] S. G. SAmko, A. A. Kilbas, O. I. Marichev, Fractional Integrals and Derivatives, Theory and Applications, Gordon and Breach, Yverdon 1993 (1993) 44.

[38] J. Vanterler da C. Sousa, E. Capelas de Oliveira, L. A. Magna, Fractional calculus and the ESR test, AIMS Math. 2 (4), (2017), 692-705. 
[39] J. Vanterler da C. Sous a, M. N. N. dos Santos, L. A. Magna, E. Capelas de Oliveira, Validation of a fractional model for erythrocyte sedimentation rate, Comput. Appl. Math., 37(5), (2018), 6903-6919.

[40] J. Vanterler da C. Sousa, E. Capelas de Oliveira, A Gronwall inequality and the Cauchytype problem by means of $\psi$-Hilfer operator, Diff. Equ. Appl., 11(1), (2019), 87-106.

[41] J. VAnterler Da C. Sous a, E. CApelas DE Oliveira, On the $\psi$-Hilfer fractional derivative, Commun. Nonlinear Sci. Numer. Simulat. 60, (2018), 72-91.

[42] J. VAnterler da C. Sousa, E. CApelas de Oliveira, Leibniz type rule: $\psi$-Hilfer fractional operator, Commun. Nonlinear Sci. Numer. Simulat. 77, (2019), 305-311.

[43] J. VAnterler Da C. Sousa, E. CAPelas De Oliveira, On the stability of a hyperbolic fractional partial differential equation, Diff. Equ. Dyn. Syst. (2019). https://doi.org/10.1007/s12591-019-00499-3.

[44] B. WU, S. WU, Existence and uniqueness of an inverse source problem for a fractional integrodifferential equation, Comput. Math. Appl. 68 (10), (2014), 1123-1136. 
Differential Equations \& Applications www.ele-math.com dea@ele-math.com 